\title{
Importance of fungus in feeding termites with sunflower plants
}

\author{
Zukhra Akhmedova ${ }^{1, *}$, Bakhtiyor Kholmatov ${ }^{1}$, Natalya Lebedeva ${ }^{1}$, Kahramon Rustamov ${ }^{1}$, \\ Jurabek Yakhyoev ${ }^{1}$, and Khojimurod Kimsanbayev ${ }^{2}$ \\ ${ }^{1}$ Institute of Zoology, Uzbek Academy of Sciences, Bogishamol str., 232b, Tashkent, Uzbekistan \\ ${ }^{2}$ Tashkent State Agrarian University, University str., 2, Tashkent province, Uzbekistan, 100140
}

\begin{abstract}
Fungal species were isolated from samples of damaged sunflower. The strains selected on the basis of cultural and morphological characteristics belonged to the species Alternaria alternata, Alternaria tennus and Fusarium oxysporum, Fusarium solan, and fungal strains were identified, as well as fungal strains, and fungal strains 67 , termites, termarium, oxolbate 10 , oxoliban 10 - to termites, oxolbate 10 - to termites, oxolbate $10.9 \%$.
\end{abstract}

\section{Introduction}

Representatives of the termite group of insects (Isoptera) are very common in nature and they live in communities in various ecological environments associated with the soil. There are currently 2,800 species of termites known. Of these, 120 species were recorded as pests $[1,2]$.

Termites have been steadily increasing in numbers over the centuries, constantly expanding their habitat, and are also attacking urbanized biogeocenoses and agrocenoses in extreme conditions. Two species of the genus Anacanthotermes belong to the genus Anacanthotermes: Turkestan (A. turkestanicus Jacobs) and the Great Trans-Caspian ( $A$. ahngerianus Jacobs.). Especially in the last 20-30 years in almost all regions of the country inhabited houses, agricultural buildings and historical, causing great damage to monuments $[3,8]$. Today, special attention is paid to the development of effective means of combating termites, as well as the protection of buildings, strategic sites and cultural and historical monuments from them.

In order to develop a strategy for the control of termites of the genus Anacanthotermes, the identification of their natural enemies, pathogens and microorganisms is of great scientific and practical importance in the targeted control of the number of termites in terms of their biology, ecology and some functional characteristics of behavior [4, 6].

Although a number of studies have been conducted in Uzbekistan on control and prevention of termites of the genus Anacanthotermes, the available data show that termites are protected from latent lifestyles, environmental factors, functional specialization of their layers in termite nests, their large number in nests, and the ability of a small number of

\footnotetext{
* Corresponding author: z.a.akhmedova@yandex.com
} 
remaining termites to regenerate their populations at a rapid rate complicates existing control measures $[5,7]$.

Given the above, one of the most pressing issues today is the development of environmentally friendly, improved, highly effective methods of combating termites.

Therefore, in order to improve the toxic feeds used in practice today, there is a need to increase the attractiveness of the feed and to facilitate the delivery of feed. This leads to an increase in the biological efficiency and duration of exposure of the feed, which in turn plays an important role in the control of termites of the genus Anacanthotermes $[3,9,10]$.

It was found that sunflower stalks, which are used as a food substrate in the preparation of termite forage, are left in the ground for a while, then dark, in some cases covered with gray fungus, and forage made from sunflower stalks covered with this fungus is preferred by termites. At the same time, in order to improve the toxic feed, there is a need to increase the attractiveness of the feed, and we aim to study the species composition and morphocultural properties of these fungi.

\section{Materials and methods}

As research materials, different age groups of termites belonging to the genus Anacanthotermes - working termites were studied. The research was conducted in the Laboratory of Ecology of Entomophages and Theoretical Foundations of Biosteres of the Institute of Physiology of the Republic of Uzbekistan. Research work on the detection of thermocidal substances that attract termites was carried out in the laboratory $[5,11,12]$.

In order to determine the most optimal content in the nutritional properties of termites of the genus Anacanthotermes, a sunflower plant was selected to determine the type of microscopic fungi that grow naturally.

In order to distinguish microscopic fungal species from the upper part of the sunflower plant, the following steps were taken:

'Chapeka' nutrient medium was selected and prepared for the isolation of fungal strains. To do this, the reagents that make up the nutrient medium were weighed on an electronic scale according to the recipe and dissolved in 1 liter of water. The finished mixture was sterilized in an autoclave at a pressure of $1 \mathrm{~atm}$ for $20 \mathrm{~min}$ by adding $16 \mathrm{~g}$ of agar to 1 liter. Sterilized water and agar agar were prepared in test tubes for planting in Petri dishes by diluting the fungi $[9,13]$ (Table 1).

Table 1. 'Chapeka' nutritional environment per 1 liter

\begin{tabular}{|l|l|l|}
\hline$\#$ & Contents & Grams \\
\hline 1 & Sucrose & 20 \\
\hline 2 & $\mathrm{KH}_{2} \mathrm{PO}_{4}$ & 1 \\
\hline 3 & $\mathrm{MgSO}_{4}$ & 0,5 \\
\hline 4 & $\mathrm{KCI}_{2}$ & 0,5 \\
\hline 5 & $\mathrm{NaNO}_{3}$ & 3 \\
\hline 6 & $\mathrm{FeSO}_{4}$ & Footprint \\
\hline \multicolumn{2}{|l}{$\mathbf{~} \mathbf{~} \mathbf{6 , 8}$} \\
\hline
\end{tabular}

Sterilized 'Chapeka' nutrient medium was poured into a box petriles in a volume of 10 $\mathrm{ml}$, and after the nutrient medium in the cup had solidified, the suspension was prepared by pouring sterile water from the stem of the Sunflower plant into sterile water solutions inside and out.

1. Add $0.5 \mathrm{ml}$ of suspension from the suspension to the agar cups and rub the whole cup with a spatula. 
2. From the stem part was planted black and white bark and the inner part was planted in the cup petri using a microbiological 'petlichka' using the fork zigzag and fork method.

Planted cups were grown in a thermostat for 6-7 days at $28-30^{\circ} \mathrm{C}$ [5], and the culturalmorphological characteristics of the grown fungi were determined. Cultural features were determined by the shape and size of the mycelium, while the morphological features of the color and structure of fungal colonies. The experiments were performed under a digitized binocular NLCD-307V-2 microscope [4, 9, 14].

The biological activity of isolated fungal strains against termites was studied. To do this, 20 working termites were placed on clay wormwood and sterilized Petri dishes. Appropriate concentrations of drugs are soaked $2 \times 2 \mathrm{~cm}$. sized filter paper was placed in Petri dishes and given to the termites as food. Each experiment was placed in 5 repetitions. The suspension of the fungi was soaked in $1.0 \mathrm{ml}$ of filter paper used as feed. Distilled water was added to the filter paper in a Petri dish with termites in the control variant. Petri dishes with termites were stored in a cool, dark place. Each day, the experimental options were checked, calculated, and recorded in a daily journal. The number of surviving, paralyzed and dead termites was calculated. Each day, the filter paper in the Petri dish containing the surviving termites was moistened with $0.02 \mathrm{ml}$ of distilled water. The experiment was followed for 10 days.

Distilled water was added to the filter paper in a Petri dish containing termites in the control variant. The number of termites was calculated by examining the experimental options daily. The experiment was followed for 10 days. Biological efficacy against termites was calculated based on the Abbot formula [15].

\section{Results and discussion}

The morphological and cultural characteristics of the isolated fungi were examined by removing the stems of the sunflower plant from the black part, the white part and the stem parts from the suspension by placing them in a liquid solution in a liquid nutrient medium. Studies have shown that in the studied samples, mainly black and white fluffy-shaped colonies grew. The appearance of cultural and morphological characteristics of fungi is given in Table 2.

Table 2. Cultural characteristics and morphological features of fungi isolated from the sunflower plant

\begin{tabular}{|c|c|c|}
\hline \multirow{2}{*}{ Culture \# } & \multirow{2}{*}{$\begin{array}{c}\text { Food } \\
\text { environment }\end{array}$} & Colony view, day \\
\hline & & 7 days \\
\hline $\begin{array}{c}1 \\
\text { (upper cut black } \\
\text { part) }\end{array}$ & \multirow{3}{*}{ 'Chapeka' } & $\begin{array}{l}\text { In the early stages of colonial growth, the white- } \\
\text { gray color later turned black. The growth of the } \\
\text { colonies is fluffy, the edges are not smooth. The } \\
\text { back of the cup is black. }\end{array}$ \\
\hline $\begin{array}{c}2 \\
\text { (top cut white } \\
\text { part) }\end{array}$ & & $\begin{array}{l}\text { The colony is white, the growth is fluffy, the edges } \\
\text { are flat. The back of the cup is white to light pink. }\end{array}$ \\
\hline $\begin{array}{l}3 \\
\text { (suspension of the } \\
\text { torn part of the } \\
\text { stem) }\end{array}$ & & $\begin{array}{l}\text { Colony growth consists of fluffy colonies of a flat } \\
\text { black and white color. The back of the cup is } \\
\text { mostly black. }\end{array}$ \\
\hline
\end{tabular}


Table 3. Morphological features of fungi isolated from the sunflower plant

\begin{tabular}{|c|c|c|}
\hline \multirow{2}{*}{ Culture \# } & \multirow{2}{*}{ Species } & Colony shape and volume \\
\hline & & 7 days \\
\hline $\begin{array}{c}1 \\
\text { (upper cut black } \\
\text { part) }\end{array}$ & $\begin{array}{l}\text { Alternaria } \\
\text { alternata }\end{array}$ & $\begin{array}{l}\text { Vegetative hyphae are spread, the color is olive } \\
\text { or olive-brown during the initial growth period. } \\
\text { conidia primary and bundled } 2-5 \mu \mathrm{m} \text {, short, } \\
\text { slightly elongated, dark greenish-brown in color, } \\
\text { korichnevatye or burovatye tones; the upper part } \\
\text { of the conidia is shortened, branched in some } \\
\text { normal hallucinations, single- or multi-celled } \\
\text { diurnal obstruction. }\end{array}$ \\
\hline $\begin{array}{l}2 \\
\text { (top cut white } \\
\text { part) }\end{array}$ & $\begin{array}{c}\text { Fusarium sp. } \\
\text { Fusarium } \\
\text { oxysporum, } \\
\text { Fusarium solani }\end{array}$ & $\begin{array}{l}\text { The fast-growing fungus has a fluffy } \\
\text { appearance, the mycelium is white, growing } \\
\text { upwards. The colonies are densely white. The } \\
\text { microconidia are approximately } 5 \times 62 \mu \mathrm{m} \text {. } \\
\text { Microconidia are in the form of single-celled or } \\
\text { multi-celled arches. Consists of 3-4 feathers, } \\
\text { arched oblong. }\end{array}$ \\
\hline $\begin{array}{l}3 \\
\text { (suspension of the } \\
\text { torn part of the } \\
\text { stem) }\end{array}$ & $\begin{array}{l}\text { Alternaria } \\
\text { tennus }\end{array}$ & $\begin{array}{l}\text { In an agar environment, the color ranges from } \\
\text { olive to dark brown. Gifs are colorless, then } \\
\text { green and dark olive, 3-6 microns thick. Conidia } \\
\text { are simple and sometimes branched. located as a } \\
\text { bush. However, when grown in an agar } \\
\text { environment, the primary dark olive color } \\
\text { ranges from dark olive color to dark olive color. } \\
\text { Conidia consist of 3-9 diurnal ridges. }\end{array}$ \\
\hline
\end{tabular}

During the study, 15 different strain species were isolated from the black and white parts of the bark part of the sunflower plant. When the morphological and cultural characteristics of the isolated strains were studied and traditionally identified, it was found that they belonged mainly to the species Alternaria alternata, Alternaria tennus and Fusarium oxysporum, Fusarium solani [9].

In this case, the growth of colonies is fluffy, the edges are not smooth. The back of the cup is black. Vegetative hyphae were observed, olive-brown conidia were primary and bundled 2-5 $\mu \mathrm{m}$, slightly elongated (Figures 1 and 2).

In our next study, the effect of a $1 \times 10^{7}$ prepared suspension of fungi isolated from a sunflower plant on the biological efficacy of termites was studied. Observations were made for 3,7 , and 10 days. On the 10th day, this figure increased by $61.5 \%$. The highest biological efficacy against termites was observed in the variant fed with Fusarium oxysporum, a suspension of the fungus. Experiments showed a slight increase of $10.4-46.7$ - $67.9 \%$, respectively, on the respective days. 


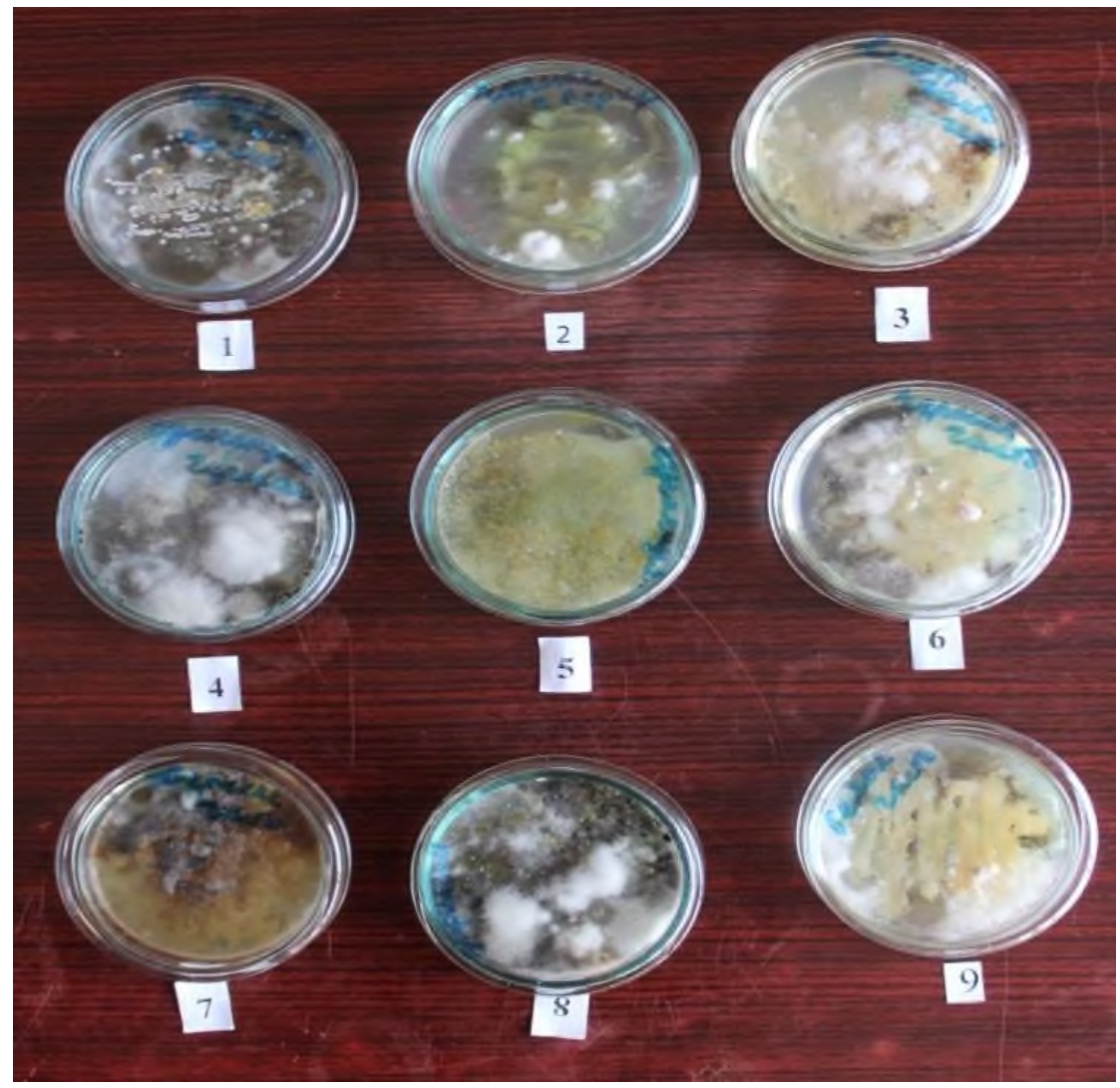

Fig. 1. State of growth after planting fungi isolated from the sunflower plant

In summary, in scientific studies: in order to determine the reasons for the preference of termites for fungal-covered sunflower stalks, 15 different strain species were isolated from the black and white parts of the bark of the plant. When their morphocultural properties were identified, it was found that Alternaria alternata, Alternaria tennus and Fusarium oxysporum belong to the species Fusarium solan, and the biological activity of fungal strains against termites Alternaria alternata, 10.4-61.5\% and Fusarium oxysporum 10.4 $67.9 \%$ formed, and it was found that these fungi play an important role in the decomposition of a certain amount of cellulose in the stem of a sunflower plant. 

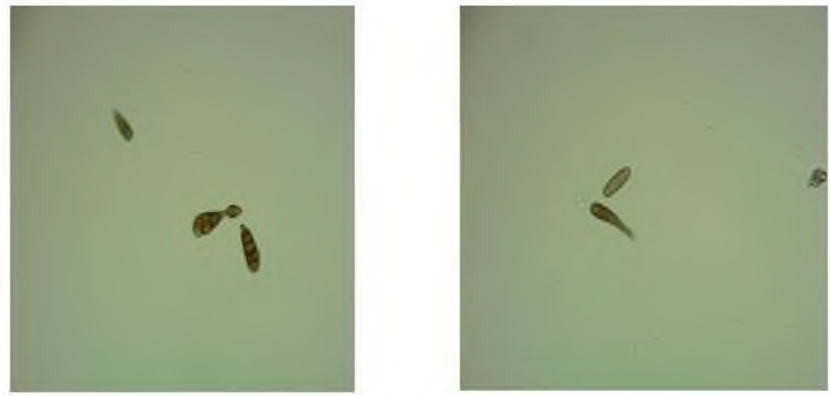

Microscopic view of the fungus Alternaria alternata isolated from the upper cut black part of the sunflower plant ( 7 days) (photos magnified 400 times)
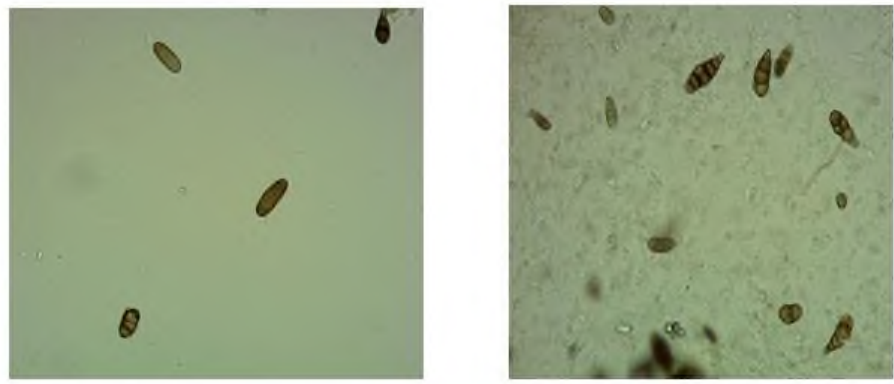

Cut part of the stem of the sunflower plant was separated from the suspension (microscopic view of the Alternaria tennuszam tube)
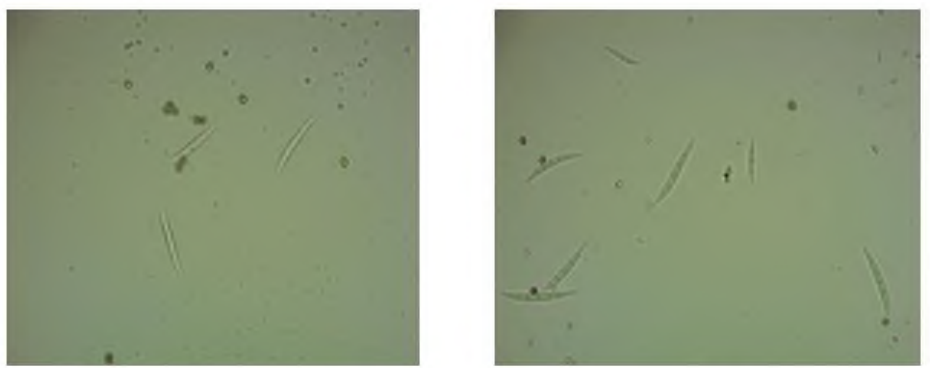

Microscopic view of Fusarium oxysporum and Fusarium solanis fungus isolated from the upper cut white part of the sunflower plant

Fig. 2. Microscopic view of fungus species

\section{Conclusion}

Fungal strains were isolated from sunflower plant samples in the stem bark layer. The strains selected on the basis of cultural and morphological features were found to belong to Alternaria alternata, Alternaria tennus and Fusarium oxysporum, Fusarium solan species. $61.5 \%$ and Fusarium oxysporum $10.4-67.9 \%$; it was found that these fungi play an important role in the decomposition of a certain amount of cellulose in the stem of a sunflower plant. 


\section{References}

1. S. Govorushko, Entomological Science 22(1), 21-35 (2019)

2. A. N. Yadav, D. Kour, T. Kaur, R. Devi, N. Yadav, Agriculturally important fungi for sustainable agriculture, 275-286 (2020)

3. N. V. Belyaeva, Termites 2, 42-44 (2014)

4. Y. Z. Tepper, V. K. Shilnikova, G. I. Pereverzeva, Workshop on Microbiology, 256 (MSU Press, Moscow, 2004)

5. A. SH. Khamraev, Journal of Plant Protection and Quarantine 3, 72-73 (2010)

6. J. Muynakbaev, Theory and practice of modern science 6(36), 4 (2018)

7. Z. Akhmedova, M. Khashimova, N. Zukhritdinova, B. Kholmatov, G. Mirzaeva, Journal of Xidian University 14(6), 3060-3065 (2020)

8. B. Kholmatov, G. Mirzaeva, K. Rustamov, I. Abdullaev, Z. Akhmedova, M. Khashimova, Journal of Plant Protection and Quarantine 3, 22-24 (2018)

9. I. Zokirov, M. Mansurkhodjaeva, Z. Akhmedova, M. Khashimova, Z. Turaeva, International Journal of Agriculture 5(2), 64-71 (2020)

10. M. Mansurkhodjaeva, Z. Ganieva, I. Zakirova, G, Mirzaeva, Z. Akhmedova, M. Khashimova, IJAR 8(11), 80-89 (2020)

11. B. Kholmatov, K. Rustamov, G. Mirzaeva, Z. Akhmedova, Journal of Plant Protection and Quarantine 3, 22-24 (2018)

12. Z. Akhmedova, M. Khashimova, European Journal of Biomedical and Pharmaceutical Sciences 3(12), 58-63 (2016)

13. M. Khashimova, Z. Akhmedova, IJSR 5(10), 264-267 (2016)

14. M. Khashimova, Z. Akhmedova, K. Rustamov, East European Science Journal 13, 1416 (2016)

15. B. Turaeva, N. Zukhritdinova, KH. Karimov, KH. Khamidova, Z. Ahmedova, EJBPS 3(9), 70-72 (2016)

16. B. Murodov, J. Yakhyoyev, Education and science in Russia and abroad, 32-36 (2017) 